\title{
Experimental study on acidification effect of tailing sand
}

\author{
Wenzhao Chen ${ }^{1, *}$, Kai Yang ${ }^{1}$, Jiaqing Fan $^{1}$, Xiqi Liu ${ }^{1}$ and Xiaoqing Wei ${ }^{1}$ \\ ${ }^{1}$ College of Civil Engineering, University of South China, Heng Yang, Hu Nan Province, 421001, China
}

\begin{abstract}
Sulfide minerals (mainly $\mathrm{FeS}_{2}$ ) contained in lead-zinc tailings are easy to be acidified in the air. The acidification mechanism is that the tailing sand generates sulfuric acid and sulfate under the catalysis of oxidant, water and oxygen. The acidic liquid generated by the reaction will continue to react with metal oxides to form an insoluble precipitate.In order to reveal the corresponding changes of chemical properties and physical properties of lead-zinc tailing sand during acidification, a series of reaction processes of tailings under natural conditions were simulated by immersion test in laboratory.It is found through the test that with the deepening of acidification, the coarse particles of tailing sand dissolve, resulting in the decrease of iron concentration in the compound, the increase of fine particles, the increase of specific surface area, the decrease of surface friction and occlusion friction between particles, resulting in the decrease of internal friction angle, and the decrease of the safety of tailings dam. words.
\end{abstract}

\section{The introduction}

In the development and utilization of mineral resources rich in metal sulfide, tailings produced by mining and dressing are one of the main solid wastes. The most common sulfide in tailings is pyrite, and the acidification of pyrite leads to the migration of thallium and toxic heavy metal ions to the environment, causing pollution to groundwater and soil ${ }^{[1]}$. The acidic waste liquid produced by the acidification of tailings will corrode the dam body of tailings dam and affect the long-term stability of tailings dam.

Scholars at home and abroad have made some exploratory studies on the acidification of tailings.Zhan Jing et al ${ }^{[2]}$ found that plant litter can effectively reduce the acidification degree of tailings, and when combined with alkaline substances like lime, it can not only slow down the acidification of tailings, but also increase the nutrient accumulation of tailings, which is conducive to the realization of ecological restoration.Liang Bing et al. $^{[3,4]}$ carried out an experimental study on the influence of acid-base solutions with different $\mathrm{pH}$ values on the compression characteristics and permeability characteristics of tailing sand.Sulfide tailings rich in carbonate may also be acidified and produce a large amount of heavy metal pollution ${ }^{[5]}$.Analysis of previous research, in view of the tail sand acidizing result in physical and mechanical properties changes mainly pauses in the macro level is only for $\mathrm{PH}$ this change were analyzed, and no in-depth analysis of the mechanism of acidizing, and the mechanism of acidification and tail ore material composition, structure and the change rule of physical and mechanical properties, So this research by conducting dynamic immersion, direct shear, consolidation, screening, bet specific surface area determination, icp iron, xrf, element analysis and a series of test research on the tail sand under different degree of oxidation - acidification mineral composition, size distribution, the change of the chemical, physical and mechanical properties such as density, and explore the relationship between the chemical and physical ways.

\section{Test mechanism}

X-ray fluorescence spectroscopy (XRF) scanning analysis of the samples showed that the lead-zinc tailing sand used in this study was mainly composed of pyrite $\left(\mathrm{FeS}_{2}\right)$, silica $\left(\mathrm{SiO}_{2}\right)$, calcium oxide $(\mathrm{CaO})$ and so on.

Pyrite is easily oxidized under natural conditions, and the recovery rate of pyrite will decrease with the extension of oxidation time ${ }^{[6]}$. The highest content of sulfide in leadzinc tailings used in this study is FeS2, which is oxidized under natural conditions. Under natural conditions, $\mathrm{FeS}_{2}$ will react under the catalysis of oxidizing bacteria, water, oxygen, ferric ion, etc. The detailed process is as follows:

$$
\begin{aligned}
& 2 \mathrm{FeS}_{2}+7 \mathrm{O}_{2}+2 \mathrm{H}_{2} \mathrm{O} \rightarrow 2 \mathrm{Fe}^{2+}+4 \mathrm{SO}_{4}^{2-}+4 \mathrm{H}^{+} \\
& 4 \mathrm{Fe}^{2+}+\mathrm{O}_{2}+4 \mathrm{H}^{+} \longrightarrow 4 \mathrm{Fe}^{3+}+2 \mathrm{H}_{2} \mathrm{O} \\
& \mathrm{FeS}_{2}+14 \mathrm{Fe}^{3+}+8 \mathrm{H}_{2} \mathrm{O} \rightarrow 15 \mathrm{Fe}^{2+}+2 \mathrm{SO}_{4}^{2-}+16 \mathrm{H}^{+}
\end{aligned}
$$

It can be seen from the equation that $\mathrm{FeS}_{2}$ first reacts with $\mathrm{O}_{2}$ and $\mathrm{H}_{2} \mathrm{O}$ and is oxidized to $\mathrm{Fe}^{2+}$ and $\mathrm{SO}_{4}{ }^{2-}$. Then $\mathrm{Fe}^{2+}$ is oxidized by $\mathrm{O}_{2}$ to $\mathrm{Fe}^{3+}$; Finally, $\mathrm{Fe}^{3+}$ is involved in the reaction, oxidizing $\mathrm{FeS}_{2}$ to $\mathrm{Fe}^{2+}$ and $\mathrm{SO}_{4}{ }^{2-}$. In summary, sulfuric acid and sulfate are the end products of the REDOX reaction of pyrite in the presence of oxygen, water and other oxidizing agents.

\footnotetext{
* Corresponding author: 912677320@qq.com
} 


\section{Test plan}

In the laboratory, $\mathrm{H}_{2} \mathrm{O}_{2}$ can be used as a catalyst to accelerate the $\mathrm{FeS}_{2}$ oxidation process, and the natural oxidation process of tailing sand can be simulated under laboratory conditions.A total of 5 groups of tests were carried out, and the oxidation degree of pyrite targets in the 5 groups were $0 \%, 25 \%, 50 \%, 75 \%$ and $100 \%$, respectively. The corresponding numbers in the tests were R00, R25, R50, R75 and R100.

In the laboratory, 5L sulfuric acid was prepared from concentrated $\mathrm{H}_{2} \mathrm{SO}_{4}$ (mass fraction 98\%) and distilled water with $\mathrm{pH}=3$.According to the mass of tailing sand and different oxidation degrees of iron $(0 \%, 25 \%, 50 \%$, $75 \%, 100 \%$ ), the amount of hydrogen peroxide required by the 5 groups of tests is calculated, and the calculation formula is as follows:

$$
V \mathrm{n}=\frac{A \times 2250 \times 15 \times 34}{30 \% \times 1.11 \times 240} \quad(\mathrm{n}=1,2,3,4,5)
$$

A: Different target oxidation degrees of $\mathrm{FeS}_{2}$.

According to calculation, in order to achieve the expected oxidation degree of $0 \%, 25 \%, 50 \%, 75 \%$ and $100 \%$ of the tailing sand sample, the hydrogen peroxide solution required is $0 \mathrm{~L}, 0.4 \mathrm{~L}, 0.8 \mathrm{~L}, 1.2 \mathrm{~L}$ and $1.6 \mathrm{~L}$.

\section{Test detection and results}

\subsection{Grain size analysis}

In order to study the change of particle size of tailing sand with different acidification degree, five kinds of tailing sand with different acidification degree were analyzed by sieving method.Standard sieves with apertures of 2.0, 1.0, $0.5,0.25$ and $0.075 \mathrm{~mm}$ were used in the test.The test results are shown in Table (1) below:

Table 1 Analysis results of tailing sand particle size under different oxidation degrees (percentage)

\begin{tabular}{|c|c|c|c|c|c|c|}
\hline Serial number & \multicolumn{5}{|c|}{ The sand/mm } & silt/mm \\
\hline & $>2$ & $1-2$ & $0.5-1$ & $0.25-0.5$ & $0.25-0.075$ & $<0.075$ \\
\hline R00 & $0.03 \%$ & $0.09 \%$ & $7.27 \%$ & $25.11 \%$ & $41.76 \%$ & $25.73 \%$ \\
\hline R25 & $0.02 \%$ & $0.09 \%$ & $7.26 \%$ & $24.29 \%$ & $44.02 \%$ & $24.34 \%$ \\
\hline R50 & $0.02 \%$ & $0.08 \%$ & $7.25 \%$ & $24.27 \%$ & $45.21 \%$ & $23.16 \%$ \\
\hline R75 & $0.02 \%$ & $0.08 \%$ & $7.05 \%$ & $23.71 \%$ & $48.00 \%$ & $21.14 \%$ \\
\hline R100 & $0.02 \%$ & $0.09 \%$ & $6.87 \%$ & $23.39 \%$ & $48.92 \%$ & $20.71 \%$ \\
\hline
\end{tabular}

$0.25 \mathrm{~mm}$ was used as the boundary value to distinguish coarse sand and fine sand, and the relative change of coarse sand and fine sand in the tailing sand was judged based on this criterion. By analyzing the test results, the mass proportion of the tailing sand with particle size greater than $0.25 \mathrm{~mm}$ decreased.The mass proportion of the tailing sand with the diameter of $0.25-0.075 \mathrm{~mm}$ increases. The mass ratio of tailing sand with particle size less than $0.075 \mathrm{~mm}$ decreases. This study through analysis the causes of this change is: $\mathrm{CaO}, \mathrm{FeS}_{2}$ coarse particles dissolve into fine particles after the reaction, so the size is greater than $0.25 \mathrm{~mm}$ particles will reduce, within the scope of 0.075 to $0.25 \mathrm{~mm}$ tail ore particles, particle size is less than $0.075 \mathrm{~mm}$ particles because of their large specific surface area that the reactivity and easily soluble is higher, so the particles contain FeS2 will dissolve in the acid liquid, so the quality of the grain size is less than $0.075 \mathrm{~mm}$ proportion is on the decline.

\subsection{Direct shear test}

According to the curve of the relationship between shear stress and shear displacement and the curve of the relationship between shear strength and vertical pressure, it can be obtained that the shear strength index of tailing sand under different oxidation degrees is cohesion $\mathrm{C}$ and internal friction Angle $\varphi$, and the specific values are shown in Table (2).
Table 2 Changes of $\mathrm{C}$ and $\varphi$ in direct shear test of tailing sand under different oxidation degrees

\begin{tabular}{|c|c|c|c|c|c|}
\hline & $0 \%$ & $25 \%$ & $50 \%$ & $75 \%$ & $100 \%$ \\
\hline $\mathrm{C}$ & 4.2 & 2.6 & 8.6 & 5.6 & 5.2 \\
\hline$\varphi$ & 31.8 & 31.3 & 31.2 & 30.5 & 29.5 \\
\hline
\end{tabular}

It can be seen from Table (2) that with the oxidation reaction, the internal friction Angle $\varphi$ will decrease.But the cohesive force $\mathrm{C}$ varies discretely. The test shows that with the increase of oxidation degree, the mechanical index of tailing sand decreases, and the safety of tailing dam decreases.

\subsection{Specific surface area measurement}

(1) Analysis of test results

The test results are shown in Figure (1) below: 


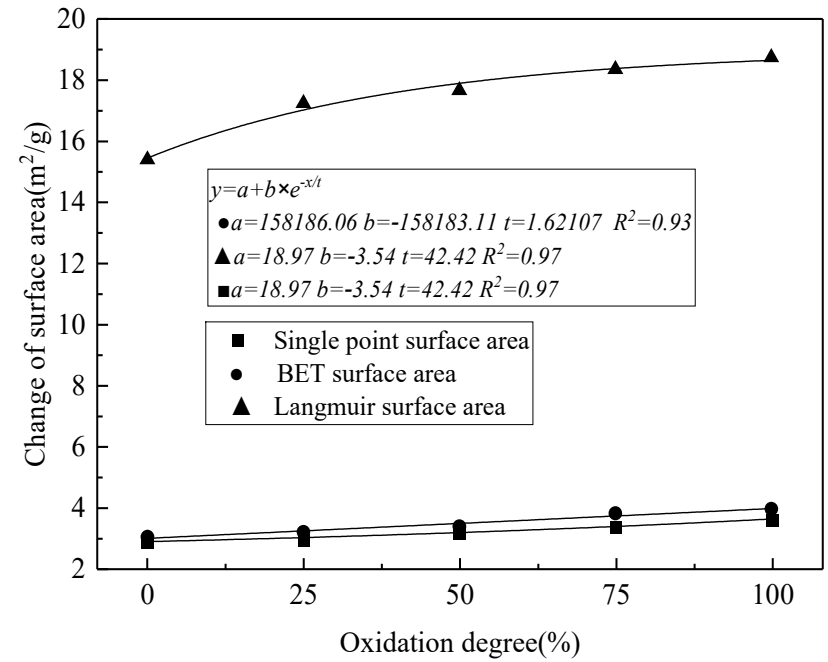

Figure 1 Broken line diagram of surface area changes of tailing sand particles under different oxidation degrees

The experimental results show that the single point surface area, BET surface area and Langmuir surface area all increase with the increase of oxidation degree.This is because as the oxidation degree rise, including $\mathrm{CaO}, \mathrm{FeS}_{2}$ coarse particle reaction after dissolved into fine particles, fine particles increase will cause the increase of specific surface area, FeS2 generated after acidification $\mathrm{Fe}_{2}\left(\mathrm{SO}_{4}\right)_{3}$ soluble in water, particle size small tail ore powder specific surface area is large, and the solution of the contact area is large, high reactivity, high solubility, so part of the tail ore powders containing $\mathrm{FeS}_{2}$ dissolved in acid liquid, lead to the small particle size powders as the degree of oxidation acidification quality decrease. The dissolution of pyrite in tailing sand is an important reason for the release of heavy metal ions such $\mathrm{As} \mathrm{Zn}, \mathrm{As}, \mathrm{Al}$ and $\mathrm{Mg}$ in acidic solution ${ }^{[7]}$. At the same time, the dissolution of heavy metal ions also leads to a slight decrease in the weight of silt particles with particle size less than $0.075 \mathrm{~mm}$ in tailing sand.

\subsection{ICP iron analysis test}

(1) Analysis of test results

The test results are shown in Figure (2) below:

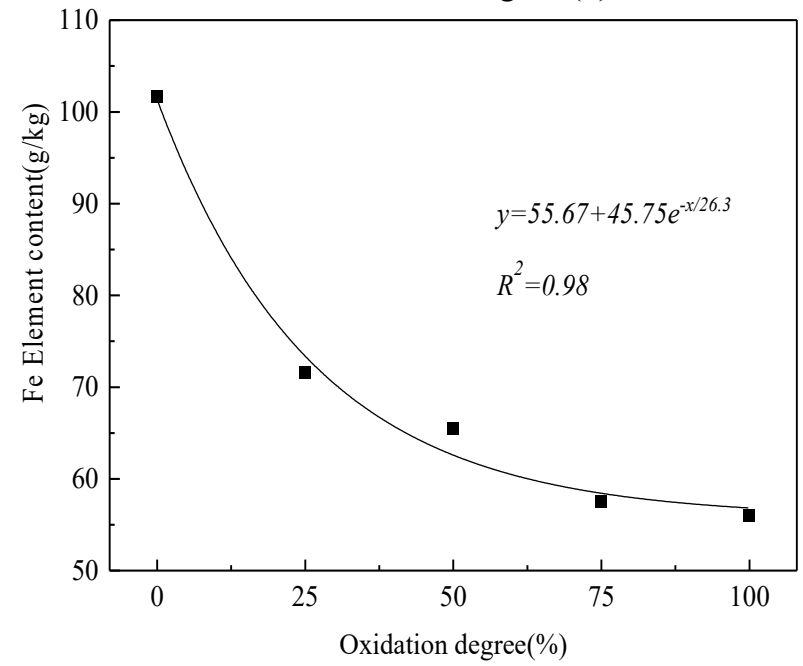

Figure 2 Broken line diagram of iron content in tailing sand under different oxidation degrees
The results show that with the increase of oxidation degree, the content of iron in the compounds decreases gradually. This is because $\mathrm{Fe}_{2}\left(\mathrm{SO}_{4}\right)_{3}$ in the tailing sand will dissolve in water after acidification reaction, and trace ferrous sulfate will dissolve faster in water. Yellow-brown acidic wastewater containing iron ions will be formed after oxidation and hydrolysis of the tailing sand.Therefore, in this experiment, it was the dissolution of $\mathrm{Fe}_{2}\left(\mathrm{SO}_{4}\right)_{3}$ particles into acidic solution that led to the reduction of $\mathrm{Fe}$ content in the compound. With the further increase of acidification, more and more $\mathrm{Fe}_{2}\left(\mathrm{SO}_{4}\right)_{3}$ particles dissolved.Fine-grained tailing sand with $\mathrm{Fe}$ element is more likely to dissolve. Therefore, the mass content of tailing sand samples with particle size less than $0.075 \mathrm{~mm}$ gradually decreases with the deepening of acidification degree.

\section{Study on the Corresponding Relationship between Physical Changes and Chemical Changes Caused by Tailings Acidification}

In order to explore the corresponding relationship between the physical and chemical changes caused by the acidification of tailings, the relationship between the content of Fe element in the compound and the internal friction Angle and specific surface area of tailings sand was established to explore the trend of its change.

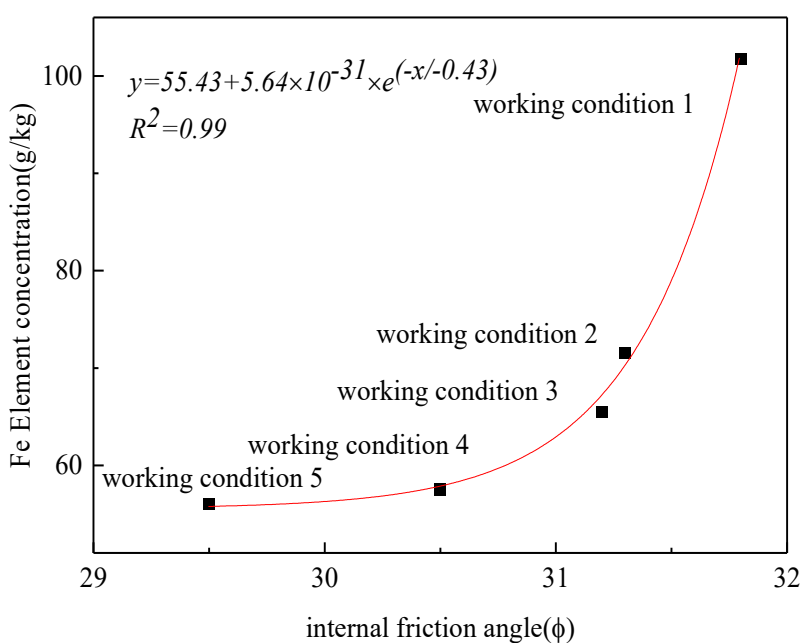

Figure 3 Broken line diagram of the relationship between Fe content in tailing sand and internal friction Angle

According to Figure (3), with the decrease of Fe content in the tailing sand, the internal friction Angle of the tailing sand gradually decreases, and the reaction degree corresponding to conditions 1 to 2 ranges from $0 \%$ to $25 \%$. Within this range, the Fe content in the compound decreases sharply, reflecting that the reaction is relatively intense at the initial stage of the reaction.To working condition of 4, tail sand internal friction Angle to decrease, but not to the variation in content of Fe element in the compound, slowly decrease, the reason is because at this stage of $\mathrm{FeS}_{2}$ oxidation reaction rate slows, other metal oxide $(\mathrm{CaO})$ and the generation of tailings acidification of sulfuric acid tail ore by double decomposition reaction in the change of physical properties. 
In order to explore the corresponding relationship between the physical and chemical changes caused by the acidification of tailings, the relationship between the content of Fe element in the compound and the internal friction Angle and specific surface area of tailings sand was established to explore the trend of its change.

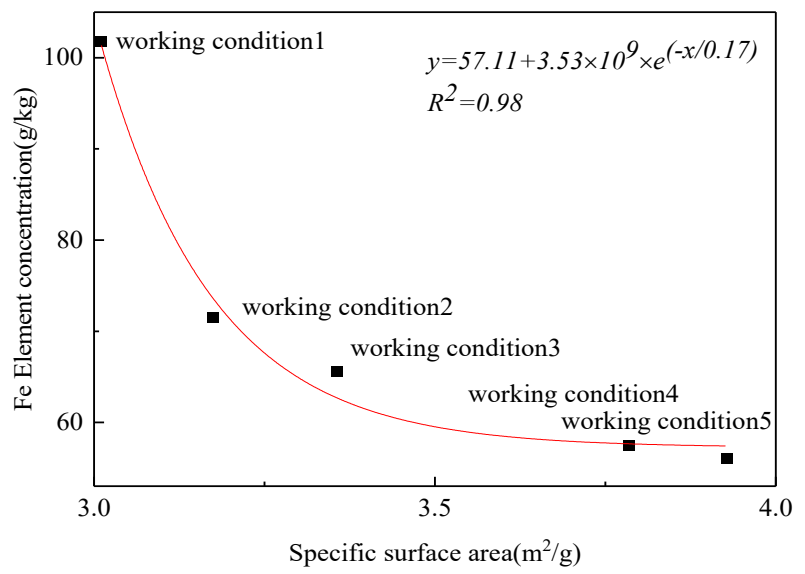

Figure 4 Broken line diagram of the relationship between $\mathrm{Fe}$ content and specific surface area in tailing sand

Figure (4) shows that the specific surface area of tailing sand gradually increases with the decrease of Fe content in tailing sand compounds, and the reaction degree corresponding to conditions 1 to 2 ranges from $0 \%$ to $25 \%$. Within this range, Fe content decreases sharply, reflecting that the reaction is intense at the initial stage of the reaction.After working condition 4 , the specific surface area of tailing sand continues to increase, but the content of Fe element changes little and decreases slowly. The reason is that the oxidation reaction rate of FeS2 slows down at this stage, and the double decomposition reaction between other metal oxides $(\mathrm{CaO})$ and the sulfuric acid generated by the acidification of tailings results in changes in the physical properties of tailing sand.

\section{6 conclusion}

The acidification degree of tailing sand will lead to the decrease of the content of coarse sand in the tailing sand, the dissolution of some silts, the mass percentage of $\mathrm{FeS}_{2}$ gradually decreases, the content of Fe element in the compound gradually decreases, the content of fine sand increases, the specific surface area increases, and the internal friction Angle $\varphi$ decreases.

Tail ore acidification mechanism under the natural condition is the tail metal sulfur minerals in the ore (mainly $\mathrm{FeS}_{2}$ ) from oxidants such as oxygen, thiobacillus ferrous oxide catalytic oxidation reaction under the action of generated sulfuric acid and sulfate, sulfuric acid produced by will and tail ore metal oxide (mainly $\mathrm{CaO}$ ) in the double decomposition reaction.During the acidification process, $\mathrm{Fe}_{2}\left(\mathrm{SO}_{4}\right)_{3}$ is generated after the acidification reaction of $\mathrm{FeS}_{2}$ and dissolved in water, and the content of $\mathrm{Fe}$ in the compound gradually decreases. In the above process, with the loss of Fe, the tailing sand with a larger particle size dissolves, making the particle size of the tailing sand become smaller, the internal friction Angle $\varphi$ gradually decreases, and the cohesion $\mathrm{C}$ is distributed discretively. The physicochemical change process of the acidification mechanism of tailings has been proved through a series of tests, which has a guiding significance for the physicochemical methods used to protect the tailings dam in the future.

With the decrease of the internal friction Angle of the soil, the consolidation settlement and sliding failure of the tailing sand accumulated in the tailings reservoir will occur, which will affect the overall stability of the tailings dam and lead to the failure of the tailings dam.the research results show that, in order to ensure the safety of tailings dam, covering the tailings dam can be used to minimize the tail ore contact with oxygen, slow down the oxidation, chemical neutralization, change the acid environment and are activated to restrain activity of thiobacillus ferrous oxide and other measures, to reduce the acidification tail ore under natural conditions, in order to ensure the safety of tailings dam.

\section{Project funds}

Key Research Project of Education Department of Hunan Province (18A252), Natural Science Foundation of Hunan Province (2017JJ3263), National Natural Science Foundation of China (51708273)

\section{References}

1. Shan Chunchang, Zhang Zhendong, Zhong Kaibin, Shi Guoling.Review and summary of treatment process of "9.8" tailings pond dam break accident in Xiangfen [J].China Emergency Management, 2011(10):13-18

2. Zhan Jing, Wang Dan, Sun Qingye.Research on metal sulfide oxidation of copper tailings covered by litter [J]. Journal of Hefei University of Technology, 2019(09):1264-1273

3. Liang Bing, Liu Yongwei, Jin Jiaxu.Experimental analysis of the compression characteristics of tailing sand under the action of acid and alkali solution [J]. Journal of Geological Hazards and Prevention, 2013,24(2):107-115

4. Zhang Yuan, Zhang Bing, Liang Bing, Zhang Erjun. Study on the Influence of Acid-base Solution on the Permeability of Sulfur-containing Tailing Sore [J].Nonmetallic Ore,2017,40(6):68-50

5. Lei Liangqi, Mo Binji, Fu Wei, Mo Jia, Shi Zhenhuan, Chen Sinai.The occurrence state of heavy metals in Bari rich carbonate sulfide tailings [J]. Earth and Environment, 2014(05):604-610.

6. Jiang Kai, Liu Jie, Han Yuexin, Li Yanjun, Zhu Yimin.Influence of natural oxidation on floatability of pyrite and its mechanism [J]. Metal Mine, 2019(02):111-114.

7. Lin Hai, Zhou Yi-hua, Dong Ying-bo, Xu Wei-juan, $\mathrm{Xu}$ Jin-mo, Wang Liang.Influence factors on bacterial leaching of zinc and arsenic from acidified sulfide ore tailings [J]. Journal of Hunan University, 2017(06):125-133. 